\title{
GDNF synthesis, signaling, and retrograde transport in motor neurons
}

\author{
Alberto F. Cintrón-Colón ${ }^{1}$ - Gabriel Almeida-Alves ${ }^{1}$ • Alicia M. Boynton ${ }^{1} \cdot$ John M. Spitsbergen ${ }^{1}$ (B)
}

Received: 17 May 2020 / Accepted: 18 August 2020 / Published online: 8 September 2020

(C) The Author(s) 2020

\begin{abstract}
Glial cell line-derived neurotrophic factor (GDNF) is a 134 amino acid protein belonging in the GDNF family ligands (GFLs). GDNF was originally isolated from rat glial cell lines and identified as a neurotrophic factor with the ability to promote dopamine uptake within midbrain dopaminergic neurons. Since its discovery, the potential neuroprotective effects of GDNF have been researched extensively, and the effect of GDNF on motor neurons will be discussed herein. Similar to other members of the TGF- $\beta$ superfamily, GDNF is first synthesized as a precursor protein (pro-GDNF). After a series of protein cleavage and processing, the 211 amino acid pro-GDNF is finally converted into the active and mature form of GDNF. GDNF has the ability to trigger receptor tyrosine kinase RET phosphorylation, whose downstream effects have been found to promote neuronal health and survival. The binding of GDNF to its receptors triggers several intracellular signaling pathways which play roles in promoting the development, survival, and maintenance of neuron-neuron and neuron-target tissue interactions. The synthesis and regulation of GDNF have been shown to be altered in many diseases, aging, exercise, and addiction. The neuroprotective effects of GDNF may be used to develop treatments and therapies to ameliorate neurodegenerative diseases such as amyotrophic lateral sclerosis (ALS). In this review, we provide a detailed discussion of the general roles of GDNF and its production, delivery, secretion, and neuroprotective effects on motor neurons within the mammalian neuromuscular system.
\end{abstract}

Keywords GDNF signaling · GDNF · Motor neuron

\section{Introduction}

Neurotrophic factors (NTFs) are a class of proteins that promote neuronal survival, control cell proliferation and differentiation, are required for axonal and dendritic elaborations, and regulate synaptic plasticity (Yan et al. 1995; Henderson et al. 1994; Zhu et al. 2008). NTFs include nerve growth factor (NGF), brain-derived neurotrophic factor (BDNF), neurotrophin-3 (NT-3), neurotrophin-4 (NT-4) belonging to the neurotrophins family, ciliary neurotrophic factor belonging to the CNTF family, and our neurotrophic factor of interest, glial cell line-derived neurotrophic factor (GDNF) belonging to the GDNF family ligands (GFLs) (Cobianchi et al. 2017; Oppenheim et al. 1995). One of the main functions of neurotrophic factors is to act as neurocytokines and, upon

John M. Spitsbergen

john.spitsbergen@wmich.edu

1 Department of Biological Sciences, Western Michigan University, Kalamazoo, MI 49008, USA synthesis and secretion, to facilitate communication between neurons and their target tissues (Morcuende et al. 2013).

GFLs have four members: GDNF, neurturin, persephin, and artemin. The members of this family have low amino acid sequence homology, but all function as homodimers for the receptor tyrosine kinase rearranged during transfection (RET) activation. GDNF was originally isolated from cultured B49 rat glial cells and found to enhance the survival and differentiation of dopaminergic neurons in primary cultures by promoting dopamine uptake (Lin et al. 1993, 1994).

The GDNF sequence places the trophic factor in the cysteine knot growth factor superfamily. Although GDNF has a low overall protein sequence similarity to TGF- $\beta 2$, the pattern of cysteine residues makes it a distant member of the TGF- $\beta$ family (Lin et al. 1993). GDNF has two finger-like structures that make contact with the GFR $\alpha$ receptor. The location where N-linked glycosylation takes place is found close to the tip of one of the finger-like structures (Eigenbrot and Gerber 1997; Parkash et al. 2008; Silvian et al. 2006). The $\mathrm{C}$-terminal of the mature GDNF has been established as highly important for its binding property to GFR $\alpha 1$ receptor and 
activation of RET (Eketjäll et al. 1999; Parkash et al. 2008). In the C-terminal of mature GDNF, we can find cysteines Cys131 and Cys133. These cysteines participate in the formation of a ring structure by linking with Cys68 and Cys 72 (Ohhashi et al. 2009).

Shortly after the discovery of GDNF, multiple researchers began identifying which cell types in the mammalian body contained and produced GDNF (Springer et al. 1995). GDNF protein is widely distributed throughout both the central and peripheral nervous systems. Synthesis and secretion of GDNF occur in many cell types such as glial cells like astrocytes, oligodendrocytes, and Schwann cells; motor neurons (MNs); and skeletal muscle. GDNF signaling has also been found within the normal growth and morphogenesis of the ureteric bud in developing the kidneys and in Sertoli cells in the testis (Henderson et al. 1994; Yan et al. 1995; Yamamoto et al. 1996; Meng et al. 2000; Costantini 2010).

GDNF has the most prominent effects on enteric, sympathetic, and dopamine neurons, but it has been identified as a potent neurotrophic factor for regulating MN survival in the peripheral nervous system (Henderson et al. 1994). GDNF prevents apoptosis of MNs during development in vivo (Oppenheim et al. 1995), decreases the loss of MNs in animal models of motor neuropathy and degeneration, rescues MNs from axotomy-induced cell death, and protects MNs from chronic degeneration ( $\mathrm{Li}$ et al. 1995; Ruven et al. 2018; Trupp et al. 1995; Sariola and Saarma 2003; Airaksinen and Saarma 2002).

\section{GDNF synthesis, secretion, and internalization}

GDNF is a secretory protein and is first formed as a precursor of 211 amino acids in mammalian cells. The pre-sequence leads the protein to the endoplasmic reticulum for secretion. As secretion takes place, the protein folds with sulfide $(\mathrm{S}-\mathrm{S})$ bonds, dimerizes, and later modified by N-linked glycosylation, and finally undergoes proteolytic processing into its mature form of 134 amino acids. This cleavage is due to a proteolytic consensus sequence located in exon II (Lin et al. 1993; Lin et al. 1994; Piccinini et al. 2013).

Proteases that play a role in the cleavage of pro-GDNF to mature GDNF are furin, PACE4, and protein convertases PC5A, PC5B, and PC7 (Lonka-Nevalaita et al. 2010). The protein convertase family is responsible for posttranslational modifications of GDNF by cleaving five consensus sites giving rise to four different peptide forms of processed GDNF. In addition, GDNF proteins with a mutation in the established furin-consensus sequence were secreted as unprocessed forms or forms with lower molecular weights compared with mature forms obtained from wild-type GDNF-overexpressing C6 cells used by Oh-hashi et al., suggesting that GDNF can be secreted with or without processing by furin-like proteases (Immonen et al. 2008; Oh-hashi et al. 2009).

Proper glycosylation is required for correct processing of GDNF protein. Piccinini et al. developed a mutant variant with an altered amino acid sequence which affected the folding of the protein. The mutant was compared with wild-type GDNF (with unchanged sequence) that was expressed in the presence of tunicamycin. Tunicamycin is an inhibitor of $\mathrm{N}$ linked glycosylation, and when GDNF was expressed in its presence, the processing of the protein was similar to the mutant's. This data demonstrates that glycosylation is necessary for proper folding and processing of GDNF protein in mammalian cells. In addition, the mutation at the glycosylation site hindered cleavage of pro-GDNF into mature GDNF (Piccinini et al. 2013).

Piccinini et al. evaluated whether the capacity of GDNF to activate its receptor complex is affected by glycosylation. The investigators showed that the unglycosylated protein, lacking the pro-sequence, is able to activate RET via GFR $\alpha 1$ and 2 (with less affinity). It was concluded that glycosylation is not critical for receptor activation (Piccinini et al. 2013).

Humans and rodents possess a shorter GDNF mRNA transcript. This shorter transcript has a 78 base pair deletion at the very end of GDNF exon I, which results in a 26 amino acid deletion in the pro-region of the protein. The deletion in the GDNF isoform does not affect the protein proteolytic sequence (Cristina et al. 1995; Schaar et al. 1994; Wang et al. 2008). After alternative splicing, GDNF gene encodes two mRNAs, a full-length pre- $(\alpha)$ pro-GDNF and a shorter pre- $(\beta)$ pro-GDNF, both are cleaved to mature GDNF (SuterCrazzorola and Unsicker 1994; Matsushita et al. 1997; Grimm et al. 1998; Penttinen et al. 2018).

Lonka-Nevalaita et al. (2010) used primary cortical neurons and the PC-6.3 cell line (neuroendocrine cells) to study intracellular processing and secretion mechanisms encoded by the $(\alpha)$ pro-GDNF and ( $\beta$ )pro-GDNF isoforms (LonkaNevalaita et al. 2010; Pittman et al. 1993). The research group found that, when an increase in $\mathrm{K}-\mathrm{Cl}$-induced depolarization occurs, $(\beta)$ pro-GDNF and its corresponding mature GDNF secretion increased, but there was no increase of $(\alpha)$ proGDNF and its corresponding mature GDNF. In addition, after immunofluorescence analysis, it was noticed that $(\alpha)$ proGDNF and its corresponding mature GDNF were mostly localized in the Golgi complex and colocalizes with Rab3A and Rab27A (two markers for secretory granules). Furthermore, after stimulation, there is a gradual movement along the secretory pathway. In contrast, $(\beta)$ pro-GDNF and its corresponding mature GDNF are mainly localized in secretogranin II and Rab3A- and Rab27A-positive vesicles, and after stimulation there is a more rapid movement along the secretory pathway (Lonka-Nevalaita et al. 2010; Wang et al. 2008).

Oh-hashi et al. established stable C6 cells that overexpressed GDNF. These cells allowed them to monitor 
spontaneous release of the protein, as well as its processed forms in the cells. The researchers increased GDNF secretion by stimulating the cells with high potassium and inhibited glycosylation with tunicamycin or disturbed ER-Golgi transport with brefeldin A. The wild-type GDNF-overexpressing C6 cells secreted three forms of processed GDNF. After treatment with tunicamycin, GDNF secreted with the highest molecular weight showed the same mobility on electrophoresis as recombinant human GDNF missing a whole pro-domain (Ohhashi et al. 2009). When mutations occurred in the prodomain and two cysteines located at the C-terminal of GDNF protein, secretion to the culture medium was significantly decreased. This data suggests that pro-domains and Cterminal cysteines of GDNF have a critical role in its processing and secretion in cultured astrocytes and C6 cells (Oh-hashi et al. 2009).

An important aspect of GDNF internalization is the encapsulation of the neurotrophic signal by endocytosis of both receptor and ligand. RET receptor when activated by GDNF has been uncovered to associate with AP2 and clathrin at the plasma membrane and possibly facilitating clathrin-mediated endocytosis similarly to NGF (Beattie et al. 2000; Crupi et al. 2015; Howe et al. 2001). Further studies are required to understand long-distance trafficking of GDNF.

SorLA is a member of the sortilin-related receptor family that is unified by the vacuolar protein sorting protein $10 \mathrm{p}$ domain (Jacobsen et al. 1996; Glerup et al. 2013; Willnow et al. 2008). SorLA possesses a cytoplasmic tail with a number of consensus binding sites for adaptor proteins that aid internalization from the cell surface, Golgi-endosome transport, and retrograde sorting to the trans-Golgi network (Nielsen et al. 2007). Glerup et al. (2013) studied the mediating interactions of SorLA as a sorting receptor for the GDNF/GFR $\alpha 1$ complex, leading the complex from the cell surface to endosomes. GDNF subsequently is targeted by lysosomes, and GFR $\alpha 1$ is recycled, thus making an effective clearance pathway. Furthermore, the SorLA/GFR $\alpha 1$ complex targets RET for endocytosis but not for degradation, which affect neurotrophic activities caused by GDNF like the survival of primary dopaminergic neurons (Glerup et al. 2013). Further studies are needed to understand GDNF internalization and trafficking.

\section{GDNF signaling}

The RET receptor occurs in the central and peripheral nervous system during development (Sanicola et al. 1997). GDNF and the rest of the GLFs use RET as a signaling receptor, but RET can only be activated in the presence of a co-receptor glycosylphosphatidylinositol-linked GDNF (GFR $\alpha)$. As previously reviewed by Sariola and Saarma, ligand-binding specificity for the GFLs is dependent on the GFR $\alpha$ receptor proteins. There are a total of four GFR $\alpha$ proteins that interact with the GFLs: GFR $\alpha 1, \operatorname{GFR} \alpha 2, \operatorname{GFR} \alpha 3$, and GFR $\alpha 4$. GDNF preferably binds to GFR $\alpha 1$, but studies using GFR $\alpha 1$ knockout mice suggest that GDNF can act via GFR $\alpha 2$ with less affinity (Cacalano et al. 1998; Sariola and Saarma 2003; Schuchardt et al. 1994; Jing et al. 1997; Enomoto et al. 1998).

GDNF is functional when it is a homodimer stabilized by a disulfide bond. GDNF first binds to a lipid raft-resident glycosylphosphatidylinositol (GPI)-anchored GFR $\alpha 1$ receptor (preferentially) and forms a high-affinity complex as shown in Fig. 1A. This complex brings two RET molecules causing transphosphorylation of specific tyrosine residues in their domains and intracellular signaling (Butte 2001; Jing et al. 1996; Stromberg et al. 1993; Trupp et al. 1995; Sariola and Saarma 2003; Airaksinen and Saarma 2002). The activation of RET triggers the mitogen-activated protein kinase (MAPK), phosphoinositositide-3-kinase (PI-3K), Erk, and Akt pathways which are attributed to act in promotion of cell survival (Airaksinen and Saarma 2002; Sariola and Saarma 2003; Kim and Kim 2018).

Membrane microdomains are enriched with signaling proteins like the Src family kinases (SFK). This enrichment has led to the reasoning that these microdomains could function as a specialized signaling organelle (Anderson 1998). Work from Tansey et al. (2000) showed that, to obtain maximal levels of GDNF-mediated bioactivity and efficient downstream signaling, RET has to be recruited to lipid rafts by GFR $\alpha 1$ receptors and interact with SFKs found in these microdomains. In addition, SFKs only interact with RET when the receptor is located on the membrane microdomains (Tansey et al. 2000). Encinas et al. (2001) studied the RETSFK association in downstream signaling caused by GDNF. The researchers found SFK activity, in particular p60Src, was needed for best GDNF-mediated Akt and MAPK phosphorylation. In addition, Src promoted neuronal survival through PI-3K pathway activity. When a PI-3K inhibitor is used, it prevented GFL-mediated and Src-mediated neuronal survival, but it had no effect on NGF-mediated survival, suggesting Src was particular for the GFL-mediated neuronal survival. Taking this data together, the researchers suggest Src as major signaling molecule for GDNF-mediated bioactivity (Encinas et al. 2001).

GDNF signaling can occur without the presence of RET. GFR $\alpha$ is more widely expressed in the nervous system compared with RET (Trupp et al. 1997; Yu et al. 1998). That being the case, GFR $\alpha$ receptors should have an alternate way to signal, independent from RET, probably with novel transmembrane proteins (Poteryaev et al. 1999; Trupp et al. 1999). Neural cell adhesion molecule (NCAM) is an adhesion molecule found in the nervous system and in the skeletal muscle, and it is involved in cell migration, synaptic plasticity, and neurite outgrowth during development (Crossin and Krushel 


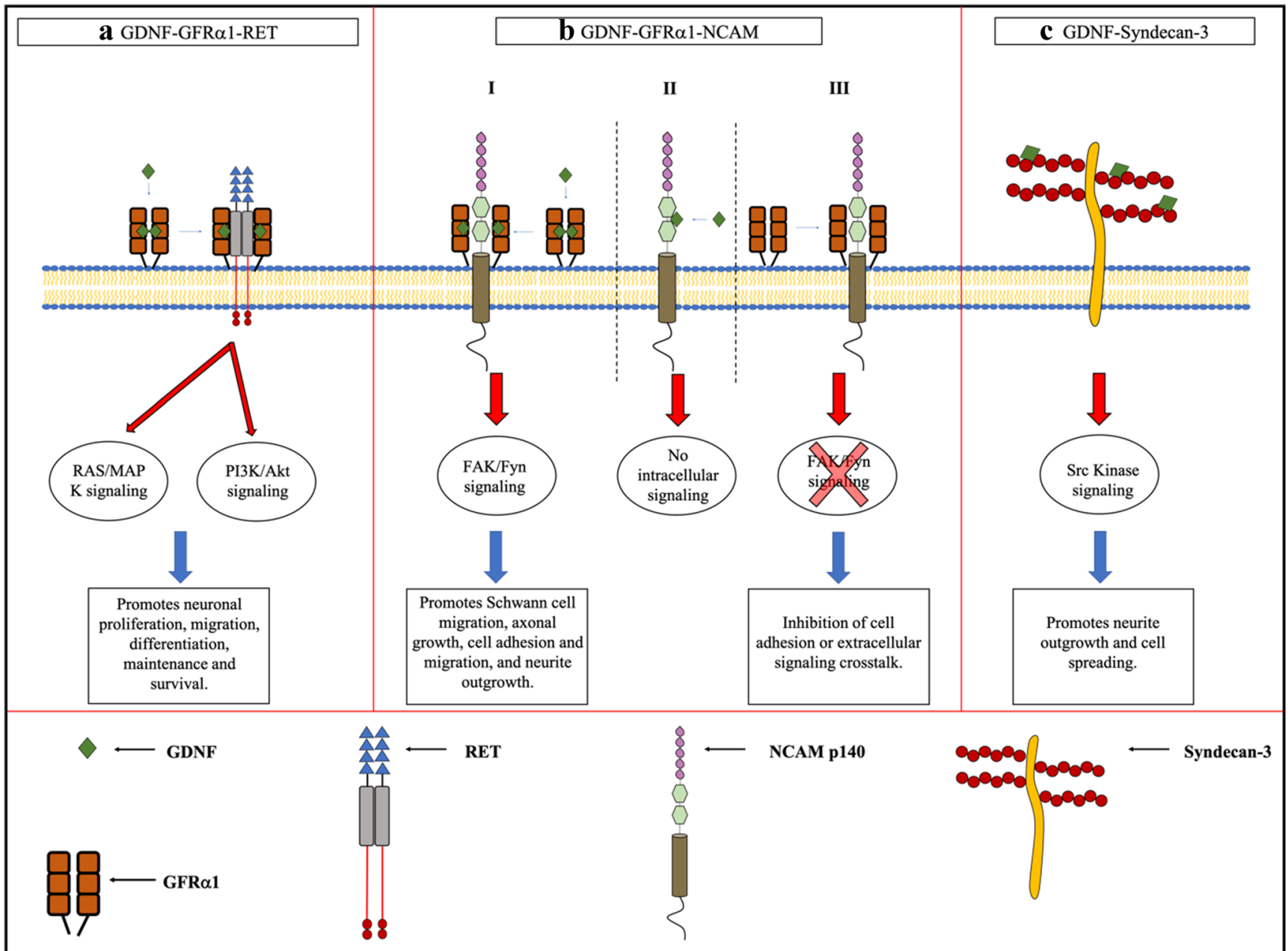

Fig. 1 GDNF and its receptors. A GDNF-GFR $\alpha 1-$ RET receptor signaling. A functional GDNF dimer associates with a GPI-anchored GFR $\alpha 1$ receptor. The GDNF-GFR $\alpha$ complex links with a RET tyrosine kinase receptor. The GDNF-GFR $\alpha 1$-RET complex triggers intracellular signaling pathways that promote neuronal survival. B GDNF-GFR $\alpha 1$-NCAM receptor signaling. B-I GDNF binds to a GFR $\alpha 1$ receptor. The GDNFGFR $\alpha 1$ complex associates with the NCAMp140 isoform and triggers

2000; Ronn et al. 2000; Schachner 1997). Paratcha et al. studied RET-independent signaling by GDNF in both glial and neuronal cells. They found a compelling similitude with intracellular pathways that were activated by the $\mathrm{p} 140^{\mathrm{NCAM}}$ NCAM isoform. The researchers demonstrated that the NCAM isoform interacts directly with GDNF family ligands along with GFR $\alpha$ receptors and mediates GDNF signaling with no RET presence. GDNF acting via the NCAM pathway promotes Schwann cell migration and axonal growth in cortical and hippocampal neurons (Paratcha et al. 2003). GFLs, when GFR $\alpha$ receptors are present, can bind with $\mathrm{p} 140^{\mathrm{NCAM}}$ and activate Src-like kinase Fyn and focal adhesion kinase FAK, a non-receptor tyrosine kinase that plays a role in cytoskeletal rearrangement as shown in Fig. 1B-I. GFLs can also bind directly to the NCAM isoform, but with much less intracellular signaling. B-II GDNF or another GFL binds directly to the NCAM receptor; no intracellular signaling is triggered. B-III GFR $\alpha 1$ binds directly with NCAM without GDNF, and it causes cell adhesion inhibition. C Matrix-bound GDNF-syndecan-3 signaling. When GDNF is immobile and matrix bound, it can be associated with a transmembrane heparan sulfate (HS) proteoglycan called syndecan-3. This binding can promote neurite outgrowth and cell spreading

affinity and does not trigger any intracellular signaling as seen in Fig. 1B-II. When GDNF is not present and GFR $\alpha 1$ receptor interacts with NCAM, it inhibits NCAM-mediated cell adhesion (Fig. 1B-III), suggesting potential difference in physiological effects, but further studies are required (Beggs et al. 1997; Paratcha et al. 2003; Saarma 2009; Kim and Kim 2018).

Pozas and Ibáñez (2005) demonstrated that GDNF has the ability to promote differentiation and migration of embryonic cortical GABAergic neurons that lack both RET and NCAM, suggesting another receptor must exist mediating GDNFdependent processes in cortical development (Pozas and Ibáñez 2005; Bespalov et al. 2011). Bespalov et al. (2011) showed that GFLs (with the exception of persephin) can use a different receptor. When GFLs are immobilized and matrix bound, they can associate with a transmembrane heparan 
sulfate (HS) proteoglycan called syndecan-3 (Fig. 1C). The researchers found GFL-syndecan-3 binding mediates neurite outgrowth and cell spreading with the collaboration of Src kinase activation. They discovered that GDNF-syndecan-3 promotes migration of cortical neurons, and when mice lack either one of those components, they have a reduced number of GABAergic neurons (Bespalov et al. 2011). Altogether, these studies suggest that GDNF may act through various pathways, mediating growth, differentiation, and migration of neurons. Once GDNF binds to one of its receptors, it must be incorporated and transported.

\section{Retrograde transport in motor neurons}

Following the neurotrophic factor theory, the target cell releases a trophic "substance." This trophic substance is available in limited supply at the time of natural apoptosis during development. The trophic factor released from the target cell reaches an axon terminal, and it is shipped in a retrograde form to the cell body of the innervating neuron to promote survival (Oppenheim 1989). Retrograde spreading of a neurotrophic signal is performed by cellular internalization of the neurotrophic factor along with its receptor at the distal location. After internalization, compartmentalization into signaling endosomes occurs, followed by motor protein-based transport toward the cell body (Wu et al. 2009; Zahavi et al. 2015; Zahavi et al. 2017). Researchers have showed both retrograde and anterograde transport of GDNF (Haase et al. 2002; Leitner et al. 1999; Rind and von Bartheld 2002; Russell et al. 2000; Zahavi et al. 2015) For the purpose of this review, we will discuss retrograde transport of GDNF in MNs. Further studies are needed to better understand the physiological effects of anterograde transport in MNs.

Expression of GDNF in skeletal muscle suggests the existence of retrograde transport and signaling from target tissue, even at adult ages (Henderson et al. 1994; Nguyen et al. 1998). GDNF is considered the first MN-specific neurotrophic factor discovered (Treanor et al. 1996). Leitner et al. (1999) studied retrograde transport of some of the members of the GDNF family in vivo. The researchers performed sciatic injections with radiolabeled GDNF and neurturin and then used autoradiography to determine retrograde transport in MNs in the lumbar region of the spinal cord in adult Sprague Dawley rats. Examination of the spinal cord from the injected rats showed more radiolabeled GDNF localized to ventral MNs compared with neurturin. This result shows retrograde activity from GDNF and physiological differences in the actions of the GFLs (Leitner et al. 1999).

Haase et al. (2002) studied MNs that express the erythroblast transformation-specific (ETS) transcription factor Pea3 in a mouse model. These MNs project their axons toward the cutaneous maximus muscle and latissimus dorsi muscle, which show expression of GDNF. The researchers noticed GDNF when lost in skeletal muscle impaired motor nerve projection and downregulation of Pea3 in MNs. Due to these findings, it is suggested that retrograde transport of GDNF signaling is necessary for axon elongation and expression of Pea3 in neuronal cell bodies. In addition, the axon-promoting effects by GDNF are not merely a local event occurring in target skeletal muscle (Haase et al. 2002; Ito and Enomoto 2016).

More recent research from Zahavi et al. (2015) developed an in vitro microfluidic platform that contained $\mathrm{MN}$ somata on one side and muscle cells on the other. The cell body of the $\mathrm{MN}$ and muscle cells were connected by motor axons that extended through microgrooves to form neuromuscular junctions (NMJs) that were functional. The benefit of having this in vitro compartmentalized system separating cell bodies from their axons and target cells provides the opportunity to study local versus distal signals and monitor retrograde and anterograde transport (Taylor et al. 2005; Zahavi et al. 2015). By using this model, Zahavi and colleagues managed to characterize spatial specificity of the effects of GDNF. They noticed that when GDNF is added at the soma survival pathway signaling via AKT is activated. In contrast, when GDNF is applied at the muscle compartment side, it promoted axonal growth at the axon tips and innervation of muscle cells. In addition, the researchers were able to visualize trafficking of GDNF in a retrograde fashion, from muscle cell to neuron (Zahavi et al. 2015).

\section{Muscle-derived GDNF effects on innervation maintenance}

GDNF plays a role in maintaining the NMJ. When insufficient levels of GDNF are present, neuronal cell death can occur, resulting in compromised structure and function of NMJs. Springer et al. (1995) reverse-transcribed the total RNA from adult rat skeletal muscle and amplified it for GDNF mRNA using PCR. They found two forms of GDNF and noticed that one of the transcripts (GDNF633) was upregulated in denervated rat skeletal muscle following 1-2 weeks of an axotomy procedure. In a similar fashion, Zhao et al. (2004) studied the expression of GDNF mRNA present in four populations of skeletal muscle: healthy skeletal muscle, denervated muscle, denervated muscle receiving sensory input, and denervated muscle in which innervation was immediately repaired. The researchers concluded that denervated muscle had the greatest GDNF expression, followed by levels in the muscle that received sensory protection, and the muscle that underwent immediate repair. The healthy skeletal muscle displayed the lowest levels of GDNF mRNA, which provides strong evidence for increased expression of GDNF during reinnervation of the NMJ (Zhao et al. 2004). These results provided further 
indications of the roles of muscle innervation in determining the expression profile of alternatively spliced forms of GDNF, GDNF working as a target-derived neurotrophic factor for neurons that innervate skeletal muscle, and the effects of providing some sort of therapy on modulating GDNF synthesis (Springer et al. 1995; Zhao et al. 2004).

Duchenne muscular dystrophy (DMD) is a genetic disorder that causes alterations in dystrophin leading to muscle degeneration and frailty. A study done by Lie and Weis (1998) examined the effects of denervation in human muscle on GDNF upregulation. The researchers compared the expression of GDNF transcripts in healthy muscle, denervated muscle, and muscle biopsies from patients diagnosed with DMD. The researchers determined that GDNF expression was significantly higher in muscle that was denervated when compared with normal or DMD-affected muscle (Lie and Weis 1998). A possible reason for this result is that in DMD patients there is still partial innervation and there is less pressure in trying to maintain nerve to muscle contact when compared with denervated muscle. It is significant to note that the work done by Lie and Weis (1998) showed that GDNF mRNA expression in humans following denervation follows a similar pattern like in rats (Lie and Weis 1998; Springer et al. 1995; Zhao et al. 2004). In addition, greater levels of GDNF were expressed in cases where a patient had a rapidly progressive neurogenic atrophy. GDNF expression in patients that had DMD was not significantly different compared with that in the controls. Altogether, Lie and Weis (1998) demonstrated evidence of the role of denervation and GDNF expression, but not dystrophy. We recommend that further human studies are needed to provide more insight on the potential of using GDNF as a re-innervating and regeneration therapy.

Nguyen et al. generated a mouse model where muscle fibers make excess quantities of GDNF. The researchers noticed GDNF overexpression caused hyperinnervation at the motor end plates found in muscle fibers. GDNF made in muscle could be acting as a synaptotrophin at the NMJ. Interestingly enough, other neurotrophic factors like NT-3 and NT-4, when overexpressed, did not provoke hyperinnervation of muscle fibers (Nguyen et al. 1998).

\section{Exercise and GDNF expression}

It has been suggested that exercise is a potential approach to enhance functional recovery of central and peripheral nerve injuries, delays neurodegenerative diseases, and has a potential for regulating neurotrophic factor signaling as reviewed by Cobianchi et al. (2017). It is still not completely understood how physical activity could increase neurotrophic factor gene expression in active muscle. Wehrwein et al. (2002) explored the changes in neuromuscular activity on GDNF content in rat skeletal muscle. Rats followed 4 weeks of walk training on a treadmill, and it was noticed that GDNF protein content increased in the pectoralis major, soleus, and gastrocnemius muscle. In addition, hindlimb unloading for 2 weeks was explored, and it was noticed that GDNF protein content decreased in the soleus and gastrocnemius muscles but increased in the pectoralis major suggesting that activity-dependent regulation of GDNF occurs in rat skeletal muscle (Wehrwein et al. 2002).

McCullough et al. (2013) explored changes in GDNF protein levels in the spinal cord following exercise. The researchers demonstrated that 2 weeks of either swimming or running altered GDNF protein content levels in the lumbar spinal tissue of both young and old rats. The L1-L3 lumbar region of the spinal cord was obtained from sedentary control and exercised 6-month animals and 24-month-old animals. The spinal tissue was processed for GDNF protein content for ELISA and Western blot assays. Results showed that GDNF protein content significantly increased in lumbar spinal tissue from exercised animals compared with that from sedentary age-matched animals (McCullough et al. 2013). In addition, lumbar spinal cord sections were immunolabeled with anti-choline acetyltransferase (ChAT) for somatic MNs (Wetts and Vaughn 1996) and with anti-GDNF. It was noticed by McCullough et al. (2013) that MN cell body size and vesicle-like structures of GDNF increased in spinal tissue from the exercised rats compared with their sedentary counterpart (McCullough et al. 2013).

Using a similar exercise regimen, Gyorkos et al. (2014) discovered that 2 weeks of running and swimming training can promote changes in GDNF expression and NMJ structure in both slow- and fast-type muscles. GDNF protein content was measured using ELISA. There was a significant increase of GDNF protein content level in the soleus muscle, while the extensor digitorum longus (EDL) trended toward an increase in GDNF protein content (Gyorkos et al. 2014). The morphology of the NMJ was analyzed by using $\alpha$-bungarotoxin, which binds to nicotinic acetylcholine receptors, thus labeling the post-synaptic end plates. The total area $\left(\mu \mathrm{m}^{2}\right)$ of post-synaptic end plates significantly increased in the soleus muscle following swimming exercise compared with sedentary control animals. In contrast, the total area of end plates significantly decreased in the EDL muscle after running training, and no differences were noticed after swimming training (Gyorkos et al. 2014). Taken together, the works of McCullough et al. (2013) and Gyorkos et al. (2014) demonstrate that physical exercise is sufficient to increase GDNF protein content in the spinal cord, within skeletal muscles, and at the NMJ. In addition, it offers new insights for developing exercise regimens as a form of additional therapy and/or treatment for patients with $\mathrm{MN}$ disease. 


\section{GDNF as a potential treatment for motor neuron diseases}

Amyotrophic lateral sclerosis (ALS) is a disease that mainly affects MNs causing loss of voluntary movement. Due to the potential neuroprotective effects of GDNF, many studies have focused on ameliorating neurodegenerative diseases by adding exogenous GDNF. Researchers used human mesenchymal stem cells to deliver GDNF directly into skeletal muscle of familial ALS model rats. The rats showed increased muscular levels of GDNF, retrograde transport of GDNF protein into motor neurons, neuroprotective effects on neuron survival, and function at the neuromuscular junction (Suzuki et al. 2008).

A similar neuroprotective effect was observed in transgenic ALS mice following intramuscular injection of an adeno-associated virus (AAV) carrying the gene for GDNF (Wang et al. 2002). Wang et al. (2002) noticed that the addition of AAV-GDNF led to longer expression of transgenic GDNF in myofibers, mostly concentrated at the NMJ. In addition, the transgenic GDNF prevented motor neuron death and protected axons that innervate skeletal muscle and muscle treated with the AAV-GDNF showed atrophy inhibition (Wang et al. 2002). These studies suggest that cellular incorporation of GDNF may help prevent the neuromuscular damage associated with ALS.

Thomsen et al. used human cortical-derived neural progenitor cells modified to secrete GDNF (hNPC ${ }^{\mathrm{GDNF}}$ ) which were transplanted to the cortex of an ALS rat model (SOD $1^{\mathrm{G} 93 \mathrm{~A}}$ ). This study is the first to show the transplanted cells survived, eventually migrated, developed into mature astrocytes, and secreted GDNF protein. Results from this study showed MN protection, pathology of the disease was slowed down, and the animals experienced an increased life span. These same cells were also used in the cortex of a primate model (cynomolgus macaques) and also had noticeable GDNF expression, and negative effects relating to behavior in a period over 30 days were not observed (Thomsen et al. 2018). This study shows promise in using $\mathrm{hNPC} \mathrm{CDNF}^{\mathrm{G}}$ as possible treatment against $\mathrm{MN}$ disease. In addition, the successful use of these cells in a nonhuman primate facilitates and opens the door to further explore the $\mathrm{hNPC}^{\mathrm{GDNF}}$ and potentially use them in clinical trials for humans.

An unfortunate effect of developing an embryonic GDNF knockout mice is renal agenesis causing neonatal death (Moore et al. 1996; Sanchez et al. 1996). Studies using conditional GDNF knockouts have been developed, but none have completed total gene removal as reviewed by Duarte Azevedo et al., which has led to argumentative conclusions (Duarte Azevedo et al. 2020). Further studies are needed to fully elucidate the physiological functions of GDNF.

\section{Conclusion}

Research regarding GDNF demonstrated a variety of neuroprotective roles for mammalian neurons and, as discussed in this review, GDNF acts as a potent neurotrophic factor for MNs. Through the research performed in the past few decades, GDNF has been found to aid in establishing new synapses between MN and target tissues, promoting growth, maintenance, and survival of neurons. With advancements in research and medicine, researchers can become more adept at delivering GDNF and other neurotrophic factors as promising candidates for a new way of therapy, preventing or treating neuro-related conditions. Nevertheless, there remains a significant gap in the knowledge of the pathways triggered by the complex of GDNF and GFR $\alpha$ following its activation of RET. Hopefully, future research will address the downstream effects of this intracellular signaling pathway and other pathways which will provide a stronger relationship between GDNF and its neuroprotective properties within MNs. Enhancing our understanding of GDNF and its signaling pathways will allow for the discovery of possible therapeutic approaches for applications of a broad range of neurological disorders such as ALS. Moreover, studying active-dependent GDNF release from skeletal muscle can aid in better creating exercise regimens as additional treatment for maintenance of the neuromuscular system.

Funding This work was funded by the NIH Grant 1R15AG022908$01 \mathrm{~A} 2$ and the Western Michigan University.

\section{Compliance with ethical standards}

Conflict of interest The authors declare that they have no conflict of interest.

Ethical approval No ethical approval required.

Open Access This article is licensed under a Creative Commons Attribution 4.0 International License, which permits use, sharing, adaptation, distribution and reproduction in any medium or format, as long as you give appropriate credit to the original author(s) and the source, provide a link to the Creative Commons licence, and indicate if changes were made. The images or other third party material in this article are included in the article's Creative Commons licence, unless indicated otherwise in a credit line to the material. If material is not included in the article's Creative Commons licence and your intended use is not permitted by statutory regulation or exceeds the permitted use, you will need to obtain permission directly from the copyright holder. To view a copy of this licence, visit http://creativecommons.org/licenses/by/4.0/.

\section{References}

Airaksinen MS, Saarma M (2002) The GDNF family: signaling, biological functions and therapeutic value. Nat Rev Neurosci 3(5):383394. https://doi.org/10.1038/nrn812 
Anderson RG (1998) The caveolae membrane system. Annu Rev Biochem 67:199-225

Beattie EC, Howe CL, Wilde A, Brodsky FM, Mobley WC (2000) NGF signals through TrkA to increase clathrin at the plasma membrane and enhance clathrin-mediated membrane trafficking. J Neurosci 20: $7325-7333$

Beggs HE, Baragona SC, Hemperly JJ, Maness PF (1997) NCAM140 interacts with the focal adhesion kinase p125(fak) and the SRCrelated tyrosine kinase p59(fyn). J Biol Chem 272:8310-8319

Bespalov MM, Sidorova YA, Turnova S, Ahonen-Bishopp A, Magalhaes AC, Kulessky E, Paveliev M, Rivera C, Rauvala H, Saarma M (2011) Heparan sulfate proteoglycan syndecan-3 is a novel receptor for GDNF, neurturin, and artemin. J Cell Biol 192(1):153-169

Butte MJ (2001) Neurotrophic factor structures reveal clues to evolution, binding, specificity, and receptor activation. Cell Mol Life Sci 58: 1003-1013. https://doi.org/10.1007/PL00000915

Cacalano G, Fariñas I, Wang LC, Hagler K, Forgie A, Moore M, Armanini M, Phillips H, Ryan AM, Reichardt LF, Hynes M, Davies A, Rosenthal A (1998) GFR $\alpha 1$ is an essential receptor component for GDNF in the developing nervous system and kidney. Neuron 21(1):53-62. https://doi.org/10.1016/s0896-6273(00) 80514-0

Cobianchi S, Arbay-Plana A, López-Álvarez VM, Navarro X (2017) Neuroprotective effects of exercise treatments after injury: the dual role of neurotrophic factors. Curr Neuropharmacol 15:495-518

Costantini F (2010) GDNF/Ret signaling and renal branching morphogenesis. Organogenesis 6(4):252-262. https://doi.org/10.4161/org. 6.4.12680

Cristina N, Chatellard-Causse C, Manier M, Feuerstein C (1995) GDNF: existence of a second transcript in the brain. Mol Brain Res 32:354 357

Crossin KL, Krushel LA (2000) Cellular signaling by neural cell adhesion molecules of the immunoglobulin superfamily. Dev Dyn 218:260 279

Crupi MJF, Yoganathan P, Bone LN et al (2015) Distinct temporal regulation of RET isoform internalization: roles of clathrin and AP2. Traffic. 16:1155-1173

Duarte Azevedo M, Sander S, Tenenbaum L (2020) GDNF, a neuronderived factor upregulated in glial cells during disease. J Clin Med 9(2):456. https://doi.org/10.3390/jcm9020456

Eigenbrot C, Gerber N (1997) X-ray structure of glial cell-line derived neurotrophic factor at $1.9 \AA$ resolution and implications for receptor binding. Nat Struct Biol 4:435-438

Eketjäll S, Fainzilber M, Murray-Rust J, Ibáñez CF (1999) Distinct structural elements in GDNF mediate binding to GFR $\alpha 1$ and activation of the GFR $\alpha 1$-c-ret receptor complex. EMBO J 18:5901-5910

Encinas M, Tansey MG, Tsui-Pierchala BA, Comella JX, Milbrandt J, Johnson EM Jr (2001) c-Src is required for glial cell line-derived neurotrophic factor (GDNF) family ligand-mediated neuronal survival via a phosphatidylinositol-3 kinase (PI-3K)-dependent pathway. J Neurosci 21(5):1464-1472

Enomoto H, Araki T, Jackman A, Heuckeroth RO, Snider WD, Johnson EM, Milbrandt J (1998) GFR $\alpha 1$-deficient mice have deficits in the enteric nervous system and kidneys. Neuron 21(2):317-324. https:// doi.org/10.1016/s0896-6273(00)80541-3

Glerup S, Lume M, Olsen D, Nyengaard JR, Vaegter CB et al (2013) SorLA controls neurotrophic activity by sorting of GDNF and its receptors GFR $\alpha 1$ and RET. Cell Rep 3:186-199

Grimm L, Holinski-Feder E, Teodoridis J, Scheffer B, Schindelhauer D, Meitinger T, Ueffing M (1998) Analysis of the human GDNF gene reveals an inducible promoter, three exons, a triplet repeat within the 3'-UTR and alternative splice products. Hum Mol Genet 7:18731886

Gyorkos AM, McCullough MJ, Spitsbergen JM (2014) Glial cell linederived neurotrophic factor (GDNF) expression and NMJ plasticity in skeletal muscle following endurance exercise. Neuroscience 257: $111-118$

Haase G, Dessaud E, Garcès A, de Bovis B, Birling M, Filippi P, Schmalbruch H, Arber S, deLapeyrière O (2002) GDNF acts through PEA3 to regulate cell body positioning and muscle innervation of specific motor neuron pools. Neuron. 29:893-905

Henderson CE, Phillips HS, Pollock RA, Davies AM, Lemeulle C, Armanini M, Simpson LC, Moffet B, Vandlen RA, Koliatsos VE, Rosenthal A (1994) GDNF - a potent survival factor for motoneurons present in peripheral-nerve and muscle. Science 266:10621064

Howe CL, Valletta JS, Rusnak AS, Mobley WC (2001) NGF signaling from clathrin-coated vesicles: evidence that signaling endosomes serve as a platform for the Ras-MAPK pathway. Neuron. 32:801814

Immonen T, Alakuijala A, Hytonen M, Sainio K, Poteryaev D, Saarma M, Pasternack M, Sariola H (2008) A proGDNF-related peptide BEP increases synaptic excitation in rat hippocampus. Exp Neurol 210:793-796

Ito K, Enomoto H (2016) Retrograde transport of neurotrophic factor signaling: implications in neuronal development and pathogenesis. J Biochem 160(2):77-85

Jacobsen L, Madsen P, Moestrup SK, Lund AH, Tommerup N, Nykjaer A, Sottrup-Jensen L, Gliemann J, Petersen CM (1996) Molecular characterization of a novel human hybrid-type receptor that binds the alpha2-macroglobulin receptor-associated protein. J Biol Chem 271:31379-31383

Jing S, Wen D, Yu Y, Holst PL, Luo Y, Fang M et al (1996) GDNFinduced activation of the ret protein tyrosine kinase is mediated by GDNFR-alpha, a novel receptor for GDNF. Cell 85:1113-1124. https://doi.org/10.1016/S0092-8674(00)81311-2

Jing S, Yu Y, Fang M, Hu Z, Holst PL, Boone T et al (1997) GFR $\alpha-2$ and GFR $\alpha-3$ are two new receptors for ligands of the GDNF family. $J$ Biol Chem 272(52):33111-33117. https://doi.org/10.1074/jbc.272. 52.33111

Kim M, Kim DJ (2018) GFRA1: a novel molecular target for the prevention of osteosarcoma chemoresistance. Int J Mol Sci 19(4):1078. https://doi.org/10.3390/ijms19041078

Leitner ML, Molliver DC, Osborne PA, Vejsada R, Golden JP, Lampe PA, Kato AC, Milbrandt J, Johnson EM Jr (1999) Analysis of the retrograde transport of glial cell line-derived neurotrophic factor (GDNF), neurturin, and persephin suggests that in vivo signaling for the GFRalpha coreceptor-specific. J Neurosci 19:9322-9331

Li L, Wu W, Lin LFH, Lei M, Oppenheim RW, Houenou LJ (1995) Rescue of adult mouse motoneurons from injury-induced cell death by glial cell line-derived neurotrophic factor. Proc Natl Acad Sci 92: 9771-9775

Lie DC, Weis J (1998) GDNF expression is increased in denervated human skeletal muscle. Neurosci Lett 250(2):87-90. https://doi. org/10.1016/s0304-3940(98)00434-0

Lin LF, Doherty DH, Lile JD, Becktesh S, Collins F (1993) GDNF: a glial cell line-derived neurotrophic factor for midbrain dopaminergic neurons. Science 260:1130-1132

Lin LF, Zhang TJ, Collins F, Armes LG (1994) Purification and initial characterization of rat B49 glial cell line-derived neurotrophic factor. J Neurochem 63:758-768

Lonka-Nevalaita L, Lume M, Leppanen S, Jokitalo E, Peranen J, Saarma M (2010) Characterization of the intracellular localization, processing, and secretion of two glial cell line-derived neurotrophic factor splice isoforms. J Neurosci 30(34):11403-11413. https://doi.org/10. 1523/JNEUROSCI.5888-09.2010

Matsushita N, Fujita Y, Tanaka M, Nagatsu T, Kiuchi K (1997) Cloning and structural organization of the gene encoding the mouse glial cell line-derived neurotrophic factor, GDNF. Gene 203:149-157 
McCullough MJ, Gyorkos AM, Spitsbergen JM (2013) Short-term exercise increases GDNF protein levels in the spinal cord of young and old rats. Neuroscience 240:258-268

Meng X, Lindahl M, Hyvönen ME, Parvinen M, de Rooij DG, Hess MW, Raatikainen-Ahokas A, Sainio K, Rauvala H, Lakso M, Pichel JG, Westphal H, Saarma M, Sariola H (2000) Regulation of cell fate decision of undifferentiated spermatogonia by GDNF. Science 287: $1489-1493$

Moore MW, Klein RD, Farinas I, Sauer H, Armanini M, Phillips H, Reichardt LF, Ryan AM, Carver-Moore K, Rosenthal A (1996) Renal and neuronal abnormalities in mice lacking GDNF. Nature. 382:76-79

Morcuende S, Munoz-Hernandez R, Benitez-Temino B, Pastor AM, De La Cruz RR (2013) Neuroprotective effects of NGF, BDNF, NT-3 and GDNF on axotomized extraocular motoneurons in neonatal rats. Neuroscience 250:31-48

Nguyen QT, Parsadanian AS, Snider WD, Lichtman JW (1998) Hyperinnervation of neuromuscular junctions caused by GDNF over-expression in muscle. Science 279:1725-1729

Nielsen MS, Gustafsen C, Madsen P, Nyengaard JR, Hermey G, Bakke O et al (2007) Sorting by the cytoplasmic domain of the amyloid precursor protein binding receptor SorLA. Mol Cell Biol 27:68426851

Oh-hashi K, Ito M, Tanaka T, Hirata Y, Kiuchi K (2009) Biosynthesis, processing, and secretion of glial cell line-derived neurotrophic factor in astroglial cells. Mol Cell Biochem 323:1-7. https://doi.org/10. 1007/s11010-008-9958-3

Oppenheim RW (1989) The neurotrophic theory and naturally occurring motoneuron death. Trends Neurosci 12(7):252-255

Oppenheim RW, Houenou LJ, Johnson JE, Lin L-FH, Li L et al (1995) Developing motor neurons rescued from programmed cell death and axotomy-induced cell death by GDNF. Nature 373:344-346

Paratcha G, Ledda F, Ibáñez CF (2003) The neural cell adhesion molecule NCAM is an alternative signaling receptor for GDNF family ligands. Cell 113:867-879

Parkash V, Leppänen V-M, Virtanen H, Jurvansuu JM, Bespalov MM, Sidorova YA, Runeberg-Roos P, Saarma M, Goldman A (2008) The structure of the glial cell line-derived neurotrophic factorcoreceptor complex. J Biol Chem 283(50):35164-35172. https:// doi.org/10.1074/jbc.M802543200

Penttinen A-M, Parkkinen I, Voutilainen MH, Koskela M, Bäck S, Their A, Richie CT, Domanskyi A, Harvey BK, Tuominen RK, Nevalaita L, Saarma M, Airavaara M (2018) Pre- $\alpha$-pro-GDNF and pre- $\beta$-proGDNF isoforms are neuroprotective in the 6-hydroxydopamine rat model of Parkinson's disease. Front Neurol 9:457. https://doi.org/ 10.3389/fneur.2018.00457

Piccinini E, Kalkkinen N, Saarma M, Runeberg-Roos P (2013) Glial cell line-derived neurotrophic factor: characterization of mammalian posttranslational modifications. Ann Med 45:66-73. https://doi. org/10.3109/07853890.2012.663927

Pittman RN, Wang S, DiBenedetto AJ, Mills JC (1993) A system for characterizing cellular and molecular events in programmed neuronal cell death. J Neuro-Oncol 13:3669-3680

Poteryaev D, Titievsky A, Sun YF, Thomas-Crussells J, Lindahl M, Billaud M, Arumae U, Saarma M (1999) GDNF triggers a novel ret-independent Src kinase family-coupled signaling via a GPIlinked GDNF receptor alpha 1. FEBS Lett 463:63-66

Pozas E, Ibáñez CF (2005) GDNF and GFRalpha1 promote differentiation and tangential migration of cortical GABAergic neurons. Neuron 45:701-713. https://doi.org/10.1016/j.neuron.2005.01.043

Rind HB, von Bartheld CS (2002) Anterograde axonal transport of internalized GDNF in sensory and motor neurons. NeuroReport 13:659664

Ronn LC, Berezin V, Brock E (2000) The neural cell adhesion molecule in synaptic plasticity and ageing. Int J Dev Neurosci 18:193-199
Russell FD, Koishi K, JianG Y, McLennan IS (2000) Anterograde axonal transport of glial cell line-derived neurotrophic factor and its receptors in rat hypoglossal nerve. Neuroscience 97:575-580

Ruven C, Badea SR, Wong WM, Wu W (2018) Combination treatment with exogenous GDNF and fetal spinal cord cells results in better motoneuron survival and functional recovery after avulsion injury with delayed root reimplantation. Neuropathol Exp Neurol 1-19

Saarma M (2009) GFL neurotrophic factors: physiology and pharmacology. Encyclopedia of Neuroscience. Elsevier Academic Press, Amsterdam, pp 711-720

Sanchez MP, Silos-Santiago I, Frisen J, He B, Lira SA, Barbacid M (1996) Renal agenesis and the absence of enteric neurons in mice lacking GDNF. Nature. 382:70-73

Sanicola M, Hession C, Worley D, Carmillo P, Ehrenfels C, Walus L, Robinson S, Jaworski G, Wei H, Tizard R, Whitty A, Pepinsky RB, Cate RL (1997) Glial cell line-derived neurotrophic factordependent RET activation can be mediated by two different cellsurface accessory proteins. Proc Natl Acad Sci U S A 94:6238-6243

Sariola H, Saarma M (2003) Novel functions and signalling pathways for GDNF. J Cell Sci 116:3855-3862

Schaar DG, Sieber B, Sherwood AC, Dean D, Mendoza G, Ramakrishnan L, Dreyfus CF, Black IB (1994) Multiple astrocyte transcripts encode nigral trophic factors in rat and human. Exp Neurol 130:387-393

Schachner M (1997) Neural recognition molecules and synaptic plasticity. Curr Opin Cell Biol 9:627-634

Schuchardt A, D'Agati V, Larsson-Blomberg L, Costantini F, Pachnis V (1994) Defects in the kidney and enteric nervous system of mice lacking the tyrosine kinase receptor Ret. Nature 367(6461):380 383. https://doi.org/10.1038/367380a0

Silvian L, Jin P, Carmillo P, Boriack-Sjodin PA, Pelletier C, Rushe M, Gong B, Sah D, Pepinsky B, Rossomando A (2006) Artemin crystal structure reveals insights into heparan sulfate binding. Biochemistry 45:6801-6812. https://doi.org/10.1021/bi060035x

Springer JE, Seeburger JL, Jin HE, Gabrea A, Blankenhorn EP, Bergman LW (1995) cDNA sequence and differential mRNA regulation of two forms of glial cell line-derived neurotrophic factor in Schwann cells and rat skeletal muscle. Exp Neurol 131(1):47-52

Stromberg I, Bjorklund L, Johansson M, Tomac A, Collins F, Olson L, Hoffer B, Humpel C (1993) Glial cell line-derived neurotrophic factor is expressed in the developing but not adult striatum and stimulates developing dopamine neurons in vivo. Exp Neurol 124: 401-412

Suter-Crazzorola C, Unsicker K (1994) GDNF is expressed in two forms in many tissues outside the CNS. Neuroreport 5:2486-2488

Suzuki M, McHugh J, Tork C, Shelley B, Hayes A, Bellantuono I, Aebischer P, Svendsen CN (2008) Direct muscle delivery of GDNF with human mesenchymal stem cells improves motor neuron survival and function in a rat model of familial ALS. Mol Ther 16(12):2002-2010

Tansey MG, Baloh RH, Milbrandt J, Johnson EM Jr (2000) GFR $\alpha$ mediated localization of RET to lipid rafts is required for effective downstream signaling, differentiation, and neuronal survival. Neuron. 25:611-623

Taylor AM, Blurton-Jones M, Rhee SW, Cribbs DH, Cotman CW, Jeon NL (2005) A microfluidic culture platform for CNS axonal injury, regeneration and transport. Nat Methods 2:599-605

Thomsen GM, Avalos P, Ma AA et al (2018) Transplantation of neural progenitor cells expressing glial cell line-derived neurotrophic factor into the motor cortex as a strategy to treat amyotrophic lateral sclerosis. Stem Cells 36(7):1122-1131. https://doi.org/10.1002/stem. 2825

Treanor JJ, Goodman L, de Sauvage F et al (1996) Characterization of a multicomponent receptor for GDNF. Nature. 382:80-83

Trupp M, Ryden M, Jornvall H, Funakoshi H, Timmusk T, Arenas E, Ibáñez CF (1995) Peripheral expression and biological activities of 
GDNF, a new neurotrophic factor for avian and mammalian peripheral neurons. J Cell Biol 130:137-148

Trupp M, Belluardo N, Funakoshi H, Ibáñez CF (1997) Complementary and overlapping expression of glial cell line-derived neurotrophic factor (GDNF), c-ret proto-oncogene, and GDNF receptor-alpha indicates multiple mechanisms of trophic actions in the adult rat CNS. J Neurosci 17:3554-3567

Trupp M, Scott R, Whittemore SR, Ibáñez CF (1999) Ret-dependent and -independent mechanisms of GDNF signalling in neuronal cells. J Biol Chem 274:208885-220894

Wang CY, Yang F, He XP, Je HS, Zhou JZ, Eckermann K, Kawamura D, Feng L, Shen L, Lu B (2002) Regulation of neuromuscular synapse development by glial cell line-derived neurotrophic factor and neurturin. J Biol Chem 277(12):10614-10625

Wang Y, Geng Z, Zhao L, Huang SH, Sheng AL, Chen ZY (2008) GDNF isoform affects intracellular trafficking and secretion of GDNF in neuronal cells. Brain Res 21(1226):1-7

Wehrwein EA, Roskelley EM, Spitsbergen JM (2002) GDNF is regulated in an activity-dependent manner in rat skeletal muscle. Muscle Nerve 26(2):206-211

Wetts R, Vaughn JE, (1996) Differential vulnerability of two subsets of spinal motor neurons in Amyotrophic lateral sclerosis. Exp Neurol 141(2):248-255

Willnow TE, Petersen CM, Nykjaer A (2008) VPS10P-domain receptors - regulators of neuronal viability and function. Nat Rev Neurosci 9: 899-909

Wu C et al (2009) The coming of age of axonal neurotrophin signaling endosomes. J Proteonomics 72:46-55
Yamamoto M, Sobue G, Yamamoto K, Terao S, Mitsuma T (1996) Expression of glial cell line-derived growth factor mRNA in the spinal cord and muscle amyotrophic lateral sclerosis. Neurosci Lett 204(2):117-120

Yan Q, Matheson C, Lopez OT (1995) In vivo neurotrophic effects of GDNF on neonatal and adult facial motor neurons. Nature 373:341344

Yu T, Scully S, Yu YB, Fox GM, Jing SQ, Zhou RP (1998) Expression of GDNF family receptor components during developmentimplications in the mechanisms of interaction. J Neurosci 18: $4684-4696$

Zahavi EE, Ionescu A, Gluska S, Gradus T, Ben-Yaakov K, Perlson E (2015) A compartmentalized microfluidic neuromuscular co-culture system reveals spatial aspects of GDNF functions. J Cell Sci 128: $1241-1252$

Zahavi EE, Maimon R, Perlson E (2017) Spatial-specific functions in retrograde neuronal signalling. Traffic. 18:415-424

Zhao C, Veltri K, Li S, Bain JR, Fahnestock M (2004) NGF, BDNF, NT3 , and GDNF mRNA expression in rat skeletal muscle following denervation and sensory protection. J Neurotrauma 21(10):14681478. https://doi.org/10.1089/neu.2004.21.1468

Zhu B, Pennack JA, McQuilton P, Forero MG, Mizuguchi K et al (2008) Drosophila neurotrophins reveal a common mechanism for nervous system formation. PLoS Biol (11):e284. https://doi.org/10.1371/ journal.pbio.0060284

Publisher's note Springer Nature remains neutral with regard to jurisdictional claims in published maps and institutional affiliations. 